\title{
KOMPARASI ALGORITMA SUPPORT VECTOR MACHINES DENGAN ALGORITMA ARTIFICIAL NEURAL NETWORK UNTUK MEMPREDIKSI NILAI PERSETUJUAN KREDIT MODAL KERJA YANG DIBERIKAN BANK UMUM
}

\author{
Abu Sopian 1) \\ Program Studi Teknik Informatika \\ Universitas Mohammad Husni \\ Thamrin \\ ianprosia2@gmail.com
}

\author{
Agus Wiyatno ${ }^{2)}$ \\ Program Studi Sistem Informasi \\ STMIK Nusa Mandiri \\ gus.cvn@gmail.com
}

\author{
Albert Riyandi ${ }^{3)}$ \\ Program Studi Sistem Informasi \\ STMIK Nusa Mandiri \\ mausharing@gmail.com
}

\begin{abstract}
Credit may be meant money provision or collection that can be equavalent with that, based on credit approval or loan agreement between bank and other party who oblige lender to pay off the debt after specific terms period with interest expenses. Commercial Bank is a bank that operate its business in conventional and or based on syariah principle which is in operation provide in and out payment service. In this business operation, commercial bank provides loan/credit facility to the customer in Rupiah and foreign currency. Working capital credit is a credit used to finnance working capital purposes are depleted in one or several time the production. For example: to buy raw material, salary, rent a building, purchase merchandise and so forth. Working capital credit approval provided by commercial bank need to predict because it has increased of credit provision provided by commercial bank that can be used as measurement of economic growth and country stability or as
\end{abstract}

\section{PENDAHULUAN}

Kredit mengandung pengertian yaitu adanya suatu kepercayaan dari seseorang atau badan yang diberikan kepada seseorang atau badan lainnya yaitu bahwa yang bersangkutan pada masa yang akan datang akan memenuhi segala sesuatu kewajiban yang telah diperjanjikan terlebih dahulu (Firdaus R, Ariyanti M,2011). Kredit Modal Kerja adalah kredit yang ditujukan untuk membiayai keperluan modal kerja yang habis dalam satu atau beberapa kali produksi. Misalnya: untuk membeli bahan-bahan mentah, gaji/upah, sewa gedung/ kantor, pembelian barang-barang dagangan dan lain sebagainya. measurement of economic growth indicator from monetary sector by Bank of Indonesia. In this research will conducted working capital credit value approval prediction will be provided by commercial bank using support vector machine algorithm that is compared with artificial neutral network algorithm. From the result of testing on support vector machine algorithm using kernel dot providing the accuracy result : 68,8\% and RMSE : 11928,594 and the result acquired using artificial neutral network algorithm providing the accuracy result : 84,7\% and RMSE : 5806,350. This result shows that the best performance for working capital credit value approval provided by commercial bank is artificial neutral network algorithm.

Keywords: Credit, Working Capital Credit, Support Vector Machine, Artificial Neural Network, Commercial Bank.

Nilai persetujuan kredit modal kerja yang diberikan bank umum menurut jenis penggunaannya perlu diprediksi dengan akurat karena semakin meningkatnya nilai pemberian kredit modal kerja oleh bank umum dapat digunakan sebagai alat ukur pertumbuhan ekonomi negara, serta sebagai indikator pengukuran pertumbuhan ekonomi dari sektor moneter oleh bank indonesia.

Penelitian untuk prediksi rentet waktu telah banyak dilakukan oleh peneliti lain dengan menggunakan beberapa algoritma diantaranya adalah algoritma Support Vector Regression, Support Vector Machine With Optimal Choice of Kernel Function Parameters, dan Support Vector Machine. 
Algoritma lain yang digunakan untuk melakukan prediksi rentet waktu adalah Artificial Neural Network. Algoritma Artificial Neural Network memiliki beberapa kelebihan diantaranya adalah kemampuannya melakukan pemodelan untuk pengenalan pola (Gupta M., Jin, and Homma, 2015). Kelebihan lainnya adalah kemampuannya untuk melakukan pembelajaran berdasarkan data yang digunakan untuk pelatihan, dapat melakukan self organization atau melakukan representasi 3 dari informasi yang diterimanya dan memiliki real time operation dalam pengertian Artificial Neural Network dapat melakukan perhitungan secara parallel serta memiliki foult toleran yang tinggi. Selain memiliki kelebihan neural network juga memiliki kekurangan diantaranya membutuhkan data yang sangat besar untuk pelatihan dan memiliki konvergensi yang lambat.

Support Vector Machine (SVM) adalah sebuah algoritma yang menggunakan nonlinier mapping untuk mengubah data pelatihan asli menjadi data berdimensi tinggi (Sreelakshmi, Kumar, 2015). SVM pada awalnya dikembangkan untuk memecahkan masalah klasisfikasi, kemudian kemampuannya telah dikembangkan untuk mengatasi regresi dan pengelompokan problem. Pada masa sekarang, SVM dengan linier atau nonlinier kernel telah menjadikan satu dari kemampuan algoritma pembelajaran untuk klasifikasi sebaik untuk regresi dengan dua kemampuan utama pada data mining dengan menggunakan kernel mapping.

Kemampuan lain yang dimiliki oleh algoritma SVM adalah memiliki akurasi yang tinggi dan tingkat kesalahan yang relative kecil, kemampuan untuk model komplek nonlinear decision baoundaries, lebih mudah untuk mengatasi over fitting, tidak membutuhkan data yang terlalu besar dan dapat digunakan untuk melakukan prediksi.

Dari uraian tersebut di atas, maka dalam penelitian ini akan digunakan algoritma Suport Vector Machine dengan algoritma Artificial Neural Network untuk perbandingan tingkat akurasi dalam memprediksi nilai kredit modal kerja yang disetujui bank umum.

\section{LANDASAN TEORI}

Berikut adalah beberapa penelitian terdahulu yang terkait dengan prediksi nilai persetujuan kredit modal kerja yang diberikan bank umum, secara garis besar tinjauan pustaka dalam tesis ini meliputi:

1.Comparative Study of SVMs and ANNs in Aquifer Water Level Prediction. Penelitian ini dilakukan oleh Mohsen Behzad; Keyvan Asghari; and Emery A. Coppola Jr. (2010), dalam penelitian ini dilakukan komparasi Support Vector Machine (SVM) dengan Artificial Neurl Networks (ANN) untuk prediksi tingkat air tanah transient dengan variabel kondisi pemompaan dan cuaca. Dari hasil pengujian ditemukan kinerja pemodelan dalam hal akurasi prediksi, yaitu algoritma Support Vector Machine (SVM) mengungguli algoritma Artificial Neurl Networks (ANN). Sementara untuk model SVM yang diusulkan kesalahan relatif dari mean square error meningkat rata-rata $42 \%$ dari tahap pelatihan untuk pengujian fase, kesalahan pengujian yang sesuai dari model ANN dibesarkan oleh sekitar tujuh kali kesalahan pelatihan (Behzad M., Asghari K., and Coppola, Emery A, 2015).

2.Exchange Rate Prediction using Support Vector Machines, A comparison with Artificial Neural Networks. Pada penelitian yang dilakukan oleh Mohamad Alamili (2011), di dalam penelitian ini yang membandingkan antara metode Support Vector Machine (SVM) dengan Artificial Neurl Networks (ANN) dengan membagi data menjadi tiga buah subsets, yaitu $70 \%$ untuk training, $20 \%$ untuk validasi dan $10 \%$ untuk testing, dengan menggunakan kernel Radial Basis Function (RBF) dan kombinasi nilai antara $C=0.794328$ dan $\gamma=0.595662$ dengan menggunakan SVM menghasilkan 54.1919\% untuk training, 59.7561\% pada validasi dan $53.3333 \%$ pada testing, sedangkan untuk ANN memadukan antara $\mathrm{w}=15$ dengan hidden nodes $=30$, menghasilkan 93.4902\% untuk training, $53.1063 \%$ pada validasi dan $50.5795 \%$ pada testing (Alamili, 2011).

3.A comparative study of artificial neural networks and support vector machine for fault diagnosis. Pada penelitian ini dilakukan oleh Yuan Fuqing, Uday Kumar dan Diego Galar (2012), Penelitian ini membandingkan kinerja Artificial Neural Network (ANN) dan Support Vector Machines (SVM) dalam hal akurasi, biaya komputasi dan stabilitas. Penelitian menunjukkan Support Vector Machines (SVM) dapat mengungguli Artificial Neural Network (ANN) dua lapisan di semua tiga 
pengukuran. Artificial Neural Network (ANN) regularized memiliki kinerja terbaik di antara ANN tetapi tidak dapat mengungguli Support Vector Machines (SVM), meskipun dalam teori, dua lapisan regularized ANN memiliki kompleksitas model yang sama seperti Support Vector Machines (SVM). Pilihan teknik untuk diagnosis kesalahan adalah antara efisiensi waktu dan akurasi. Misalnya, untuk ANN, MSE yang lebih kecil mengarah ke akurasi yang lebih tinggi, tetapi memakan waktu lebih banyak pelatihan, Untuk diagnosis kesalahan, model sederhana tampaknya pilihan yang lebih baik. Orang mungkin, misalnya, pilih neuron yang lebih sedikit dalam ANN atau menggunakan agar fungsi kernel polinomial yang lebih rendah dalam SVM, sebagai model kurang kompleks bias menunjukkan kinerja yang sama atau performa yang lebih baik menimbulkan biaya komputasi (Fuqing Y., Kumar U., and Galar D., 2015).

4.Kajian penerapan artificial neural network (ANN) untuk memprediksi harga saham Mustika Ratu dengan metode support vector machines (SVM) dan multi layer perception (MLP). Penelitian ini dilakukan oleh Budi Wasito (2013), pada penelitian ini mengkaji penerapan artificial neural network (ANN) dengan metode support vector machines (SVM) dan multi layer perception (MLP) untuk memprediksi harga saham. Harga saham perlu diprediksi agar para investor tidak mengalami keruguian. Data harga saham merupakan data deret waktu yang dalam periode tertentu memiliki pola yang unik. Maka dengan menggunakan metode machine learning, penelitian mengkaji penggunaan metode support vector machines (SVM) dan multi layer perception (MLP) terkait dengan objek saham PT. Mustika Ratu. Variabel input adalah berupa harga saham historis periode tahun 2007 hingga tahun 2012. Kajian ini berusaha mengungkap tingkat root mean square error (RMSE) dan keakuratan prediksi antara support vector machines (SVM) dan multi layer perception (MLP). Disimpulkan bahwa metode pembelajaran menggunakan multi layer perception (MLP) lebih rendah dari pada menggunakan (SVM) support vector machines (Wasito, Budi, 2013).

5.Komparasi support vector machine (SVM) dan neural network (NN) untuk prediksi kelulusan sertifikasi benih kentang. Penelitian ini dilakukan oleh Usep Tatang Suryadi (2015). Pada penelitian ini mengkaji komparasi support vector machine (SVM) dan neural network (NN) untuk memprediksi kelulusan sertifikasi benih dengan menggunakan teknik datamining. Penelitian ini membandingkan akurasi algoritma Neural Network dan Support Vector Machine untuk menyelesaikan masalah prediksi kelulusan sertifikasi benih. Proses validasi menggunakan Split Validation, sedangkan pengujian model menggunakan algoritma Confusion Matrix dan ROC Curve. Hasil pengujian menunjukkan model dengan algoritma Neural Network memiliki akurasi sebesar $96.61 \%$ dan nilai AUC sebesar 0.997 sedangkan untuk algoritma Support Vector Machine memiliki nilai akurasi sebesar $98.91 \%$ dan nilai AUC sebesar 1.000. Sehingga dapat disimpulkan penerapan algoritma Support Vector Machine lebih baik dari Neural Network pada data sertifikasi benih kentang (Suryadi, Usep T, 2015).

Berdasarkan tinjauan studi diatas dapat disimpulkan bahwa telah banyak peneliti yang menggunakan komparasi algoritma support vector machine (SVM) dan artificial neural network (ANN) untuk metode prediksi. Namun belum diketahui penelitian sebelumnya yang menggunakan komparasi algoritma support vector machine (SVM) dan artificial neural network (ANN) untuk memprediksi nilai persetujuan kredit modal kerja yang diberikan bank umum.

\section{Algoritma Support Vector Machine}

Pada Conference on Learning Theory (COLT), Boser, Bernhard, Guyon, dan Vapnik tahun 1992, memperkenalkan SVM yaitu sebuah teknik supervised learning dari bidang machine learning yang dapat di aplikasikan kedalam klasifikasi dan regresi. SVM merupakan salah satu teknik yang relatif baru untuk melakukan prediksi, SVM berada dalam satu kelas dengan ANN dalam hal fungsi dan kondisi permasalahan yang bisa di selesaikan. Dalam banyak implementasi SVM memberikan hasil yang lebih baik dari ANN, dalam hal solusi yang di capai. ANN menemukan solusi berupa local optimal dimana ANN akan selalu memberikan solusi yang berbeda dari setiap training, berbeda dengan SVM yang menemukan solusi global optimal, dimana solusi akan memberikan hasil yang sama setip di jalankan.

Secara sederhana konsep SVM adalah sebagai usaha mencari hyperlane terbaik yang berfungsi 
sebagai pemisah dua buah class pada input space, dimana dapat dilihat pada gambar 2.2:

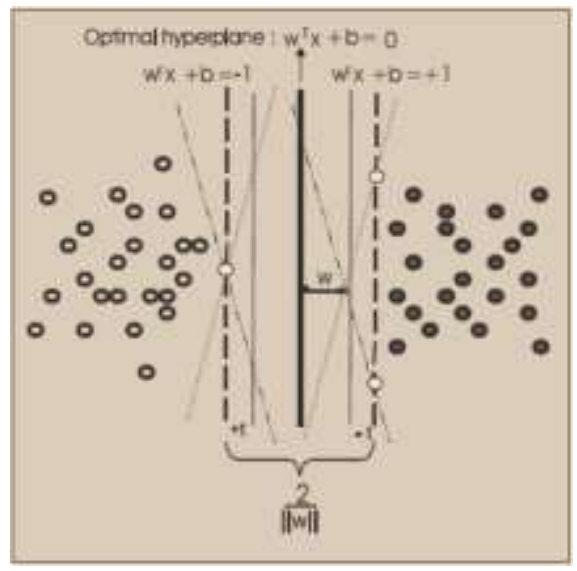

Gambar 2.2 Konsep SVM untuk mencari hyperlane terbaik

Pada gambar diatas memperlihatkan beberapa pattern yang merupakan anggota dari dua buah class: +1 dan -1. Pattern yang tergabung pada class -1 disimbolkan dengan warna kuning. Sedangkan pattern pada class +1 , disimbolkan dengan warna biru. Problem klasifikasi dapat diterjemahkan dengan usaha menemukan garis (hyperplane) yang memisahkan antara kedua kelompok tersebut. Berbagai alternatif garis pemisah (discrimination boundaries) ditunjukkan garis berwarna orange. Hyperplane pemisah terbaik antara kedua class dapat ditemukan dengan mengukur margin hyperplane tersebut. dan mencari titik maksimalnya.

Margin adalah jarak antara hyperplane tersebut dengan pattern terdekat dari masing-masing class. Pattern yang paling dekat ini disebut sebagai support vector. Hyperplane yang terbaik yaitu yang terletak tepat pada tengah-tengah kedua class, sedangkan titik putih yang berada dalam garis bidang pembatas class adalah support vector. Usaha untuk mencari lokasi hyperplane ini merupakan inti dari proses pembelajaran pada SVM.

\section{Algoritma Artificial Neural Network}

Artificial Neural Network (ANN) atau jaringan syaraf tiruan (JST) adalah suatu usaha untuk meniru fungsi otak manusia. Otak manusia diyakini terdiri dari jutaan unit pengolahan kecil, yang disebut neuron, yang bekerja secara paralel. Neuron saling terhubung satu sama lain melalui koneksi neuron. setiap individu neuron mengambil input dari satu set neuron. Ini kemudian memproses input tersebut dan melewati output untuk satu set neuron. Keluaran dikumpulkan oleh neuron lain untuk diproses lebih lanjut. Para Otak manusia adalah jaringan kompleks neuron di mana koneksi tetap melanggar dan membentuk. Banyak model mirip dengan otak manusia telah diusulkan (Shukla, A., Tiwari, R., and Kala, 2010).

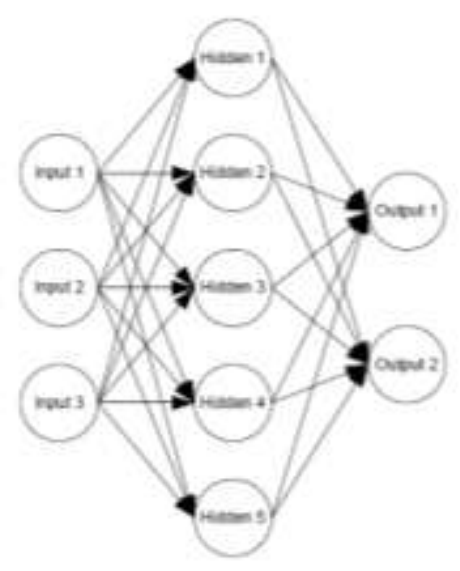

Gambar 2.4 Arsitektur Neural Network

Kemampuan otak manusia seperti: mengingat, menghitung, mengeneralisasi, adaptasi, diharapkan neural network dapat meniru kemampuan otak manusia. Neural network berusaha meniru struktur/arsitektur dan cara kerja otak manusia sehingga diharapkan bisa dan mampu menggantikan beberapa pekerjaan manusia. Pekerjaan seperti mengenali pola (pattern recognition), prediksi, klasifikasi, pendekatan fungsi, optimisasi.

\section{Pengujian K-Fold Cross Validation}

Salah satu pendekatan alternatif untuk "training dan test" yang sering di adopsi dalam beberapa kasus (dan beberapa lainnya terlepas dari ukurannya) yang di sebut dengan $k$-fold cross validation (Bramer, M, 2007), dengan cara menguji besarnya error pada data test (Santosa, Budi, 2007).

Kita gunakan k-1 sampel untuk training dan 1 sampel sisanya untuk testing. Misalnya ada 10 subset data, kita menggunakan 9 subset untuk training dan 1 subset sisanya untuk testing. Ada 10 kali training dimana pada masing-masing training ada 9 subset data untuk training dan 1 subset digunakan untuk testing. Dari situ lalu di hitung rata-rata error dan standar deviasi error. Setiap bagian $\mathrm{k}$ pada gilirannya 
digunakan sebagai ujian menetapkan dan k lainnya - 1 bagian digunakan sebagai training set.

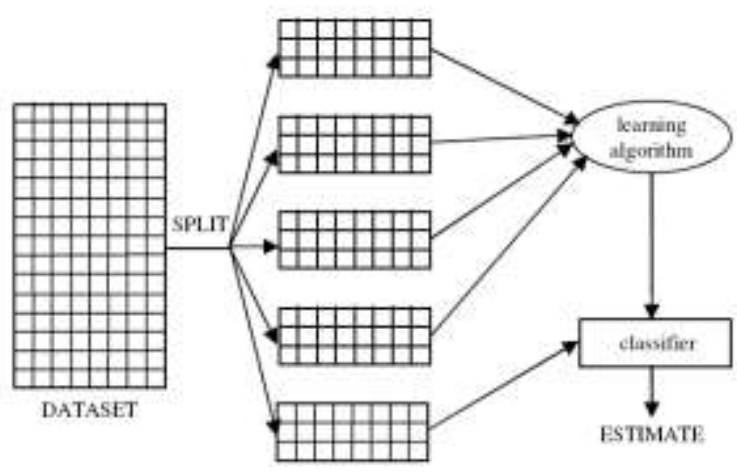

Gambar 2.5 K-fold Cross-validation

\section{Kerangka Pemikiran}

Berdasarkan gambar 2.6, model penelitian ini bertujuan untuk meneliti akurasi mana yang lebih baik dengan membandingkan penggunaan algoritma support vector machines (SVM) dan artificial neural network (ANN) untuk memprediksi nilai persetujuan kredit modal kerja yang diberikan bank umum.

Untuk pengujian hasil prediksi digunakan $x$ validation, menggunakan sepuluh langkah (10-folds cross-validation), dimana data akan dibagi menjadi sepuluh data dengan jumlah yang sama kemudian akan diambil satu persatu untuk test, dan sembilan bagian lainnya digunakan untuk training dan metode evaluasi menggunakan Root Mean Square Error (RMSE). Kerangka pemikiran terlihat pada gambar 2.6.

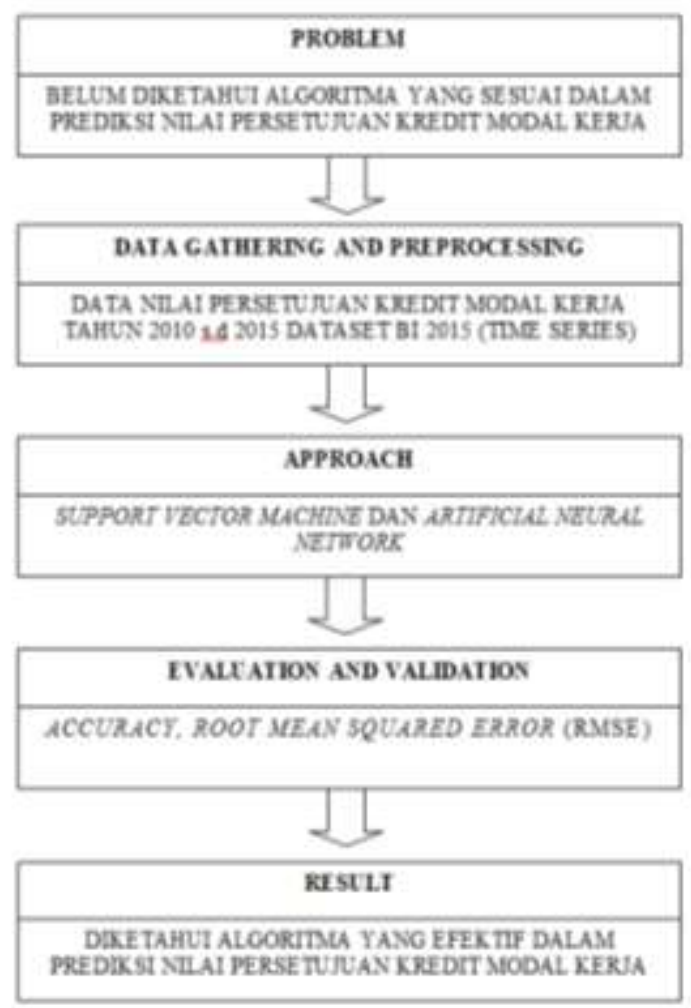

Gambar 2.6 Kerangka Pemikiran

\section{METODE PENELITIAN}

Jenis penelitian yang digunakan adalah model eksperimen. Dimana penelitian eksperimen melibatkan penyelidikan hubungan klausal menggunakan tes dikendalikan oleh si peneliti itu sendiri. Penelitian eksperimen ini menggunakan algoritma support vector machine (SVM) yang akan dikomparasi dengan algoritma artificial neural network (ANN) untuk memprediksi nilai persetujuan kredit modal kerja yang diberikan bank umum.

Pada tahap penelitian ini menggunakan pemodelan standar data mining yaitu Cross Industry Standard Process for Data Mining (CRISP-DM). Tahapan penelitian dengan menggunakan Cross Industry Standard Process for Data Mining (CRISPDM) terdiri dari tahapan pemahaman penelitian yaitu menentukan latar belakang penelitian, masalah penelitian dan batasan penelitian serta penentuan tujuan penelitian. Selanjutnya tahapan pemahaman data yaitu melakukan proses pengumpulan data untuk penelitian. Tahapan berikutnya yaitu tahapan pengolahan data, dimana data diolah agar data tersebut dapat digunakan sebagai data eksperimen. Setelah 
tahapan pengolahan data diteruskan dengan tahapan pemodelan. Pada tahap pemodelan ini membuat metode yang diusulkan dan dilakukan eksperimen/pengujian model. Tahapan selanjutnya adalah tahapan evaluasi, pada tahapan ini dilakukan evaluasi terhadap model. Dan yang terakhir adalah tahapan penyebaran. Tahapan-tahapan penelitian model Cross Industry Standard Process for Data Mining dapat dilihat pada gambar 3.1 dibawah ini (Larose, 2006).

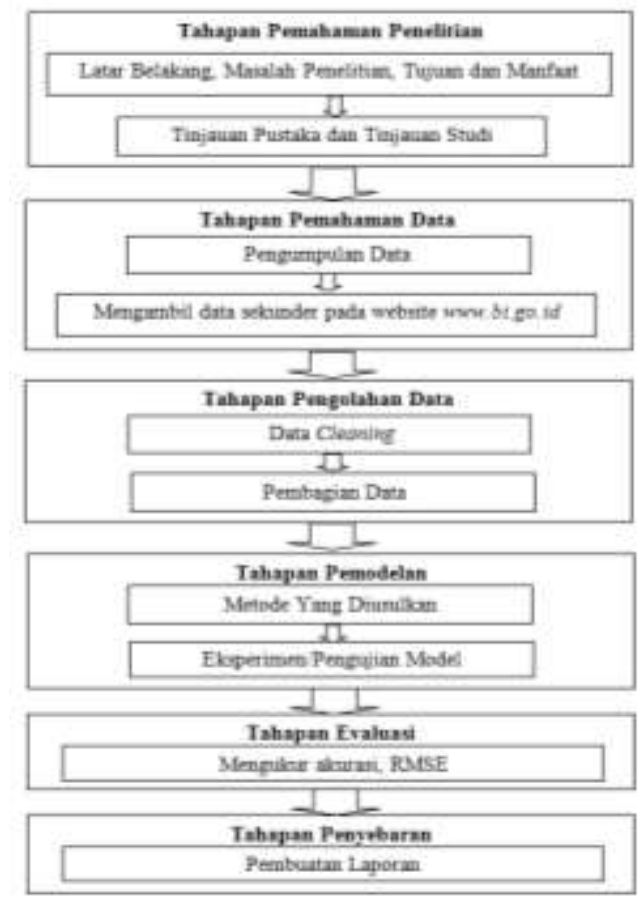

Gambar 3.1 Tahapan Penelitian

\section{Metode Yang Diusulkan}

Pada penelitian ini metode yang diusulkan yaitu dilakukan proses cleaning data dan pembagian data menjadi data training dan data testing. Selanjutnya dilakukan pemrosesan data training dari data tahun 2010 sampai dengan data tahun 2014 yang akan diuji untuk mendapatkan model. Setelah mendapatkan model dari data training, data divalidasi dengan 10 folds cross validation, selanjutnya dilakukan proses evaluasi yaitu model yang didapat dilakukan pengujian dengan data testing tahun 2015 untuk mendapatkan nilai akurasi dan nilai root mean square error (RMSE). Hasil dari nilai akurasi dan nilai root mean square error (RMSE) algoritma support vector machine (SVM) akan dikomparasi dengan algoritma artificial neural network (ANN) untuk menentukan performa algoritma mana yang terbaik. Model yang diusulkan dapat dilihat pada gambar 3.2.

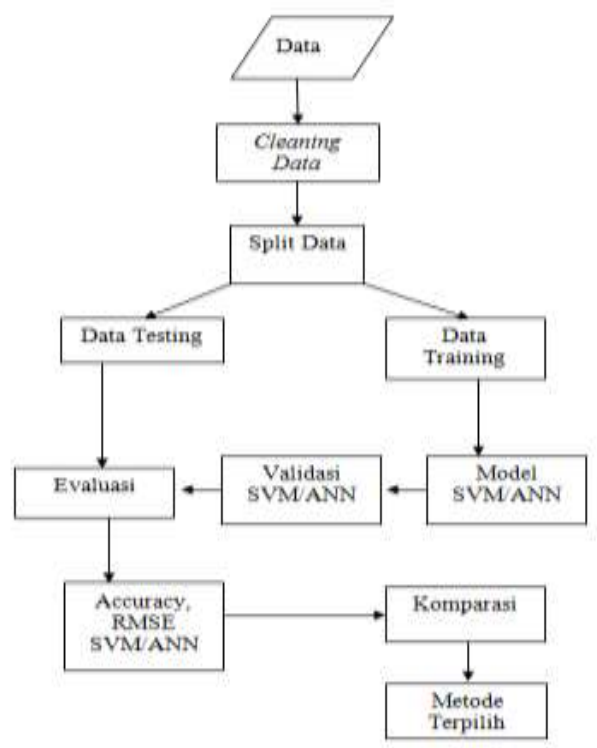

Gambar 3.2 Model Yang Diusulkan

\section{HASIL PENELITIAN DAN PEMBAHASAN}

Penelitian dilakukan dengan melakukan komparasi dua algoritma, yaitu dengan menggunakan algoritma support vector machine (SVM) dan algoritma artificial neural network (ANN). Pengujian model dengan algoritma support vector machine (SVM) yaitu dengan menggunakan pemilihan kernel. Pemilihan kernel berpengaruh terhadap tingkat akurasi serta root mean squared error (RMSE). Kernel yang akan digunakan dalam penelitian ini adalah dot, radial dan polynomial. Dengan menggunakan algoritma support vector machine (SVM) menggunakan kernel tersebut, maka akan terlihat kernel manakah yang paling sesuai dengan dataset dan mana yang bisa memberikan hasil akurasi yang optimal.

Sedangkan pengujian model menggunakan algoritma artificial neural network (ANN) dengan menentukan nilai parameter learning-rate dan momentum untuk mendapatkan hasil terbaik. Nilai parameter Trining Cycle ditetapkan yaitu 500, untuk nilai parameter learning-rate yaitu 0.3 dan nilai parameter momentum yaitu 0.2 dengan hidden layer adalah 1. Hasil dari nilai akurasi dan root mean squared error (RMSE) akan dibandingkan dengan hasil dari penggunaan algoritma support vector 
machine (SVM) untuk menentukan algoritma manakah yang lebih optimal.

Dari hasil eksperimen diatas maka untuk memilih hasil pengujian terbaik pada algoritma support vector machine (SVM) yaitu dengan melihat kecilnya nilai error yang dihasilkan dalam pengujian. Dari hasil pengujian nilai prediksi yang terbaik terdapat pada kernel dot. Dapat dilihat pada tabel 4.7 dan grafik pada gambar 4.1.

Tabel 4.7 Hasil Eksperimen Terbaik SVM

\begin{tabular}{|l|r|r|r|}
\hline & \multicolumn{1}{|c|}{ Dot } & \multicolumn{1}{c|}{ Radial } & Polynomial \\
\hline RMSE & 11928,594 & 11961,592 & 11988,526 \\
\hline $\begin{array}{l}\text { Prediction } \\
\text { Trend } \\
\text { Accuracy }\end{array}$ & $68,8 \%$ & $69,4 \%$ & $68,8 \%$ \\
\hline
\end{tabular}

Performa terbaik dari pengujian dengan menggunakan algoritma support vector machine terdapat pada kernel dot dengan nilai akurasi $=68,8 \%$, nilai $\mathrm{RMSE}=11928,594$.

Dari hasil eksperimen di atas terlihat bahwa kernel dot untuk prediksi nilai persetujuan kredit modal kerja memberikan hasil yang lebih baik dari pada kernel radial dan polynomial. Oleh karena itu untuk prediksi nilai kredit modal kerja yang disetujui oleh bank umum pada support vector machine (SVM) penulis akan menggunakan kernel dot.

Hasil dari pengujian dengan algoritma artificial neural network (ANN) dengan menentukan nilai parameter learning-rate dan momentum untuk mendapatkan hasil terbaik. Nilai parameter Trining Cycle ditetapkan yaitu 500, untuk nilai parameter learning-rate yaitu 0.3 dan nilai parameter momentum yaitu 0.2 dengan hidden layer adalah 1 dan hiddden layer size atau neuron dari hidden layer 3, 5, dan 9 dapat dilihat pada tabel dan grafik dibawah ini.

Tabel 4.8 Eksperimen Satu Hidden Layer

\begin{tabular}{|c|c|c|}
\hline \multirow{2}{*}{ Neuron Size } & RMSE & $\begin{array}{c}\text { Prediction Trend } \\
\text { Accuracy }\end{array}$ \\
\hline 3 & 6137,042 & $77,6 \%$ \\
\hline 5 & 5941,348 & $85,3 \%$ \\
\hline 9 & 5806,350 & $84,7 \%$ \\
\hline
\end{tabular}

Untuk pengujian dengan menggunakan algoritma artificial neural network (ANN) dapat dilihat pada tabel 4.8, dan dilakukan pengujian dengan pembagian data secara manual dengan membagi data training menggunakan data tahun 2010 sampai dengan data tahun 2014 dan untuk data testing menggunakan data tahun 2015.

Berdasarkan hasil eksperimen yang dilakukan untuk memprediksi nilai kredit modal kerja yang disetujui oleh bank dapat terlihat bahwa dengan menggunakan kernel dot pada algoritma support vector machine (SVM) baik dilihat pada akurasi dan RMSE memberikan hasil evaluasi yang lebih baik dari pada kernel Radial dan Polynomial, yaitu akurasi= $68,8 \%$ dan $\mathrm{RMSE}=11928,594$.

Sedangkan hasil dari pengujian dengan algoritma artificial neural network (ANN), penentuan dengan satu hidden layer dan menggunakan hidden layer size/neuron size 3 memberikan hasil yang lebih baik dibandingkan dengan pemilihan jumlah hidden layer size yang lain. Dengan menentukan nilai parameter trining cycle yaitu 500, untuk nilai parameter learning-rate yaitu 0.3 dan nilai parameter momentum yaitu 0.2 dengan hidden layer adalah 1 dan hiddden layer size atau neuron dari hidden layer 3, 5 dan 9, maka didapatkan hasil akurasi sebesar $=84,7 \%$ dan nilai RMSE sebesar $=5806,350$.

Dari hasil pengujian dapat disimpulkan bahwa, algoritma artificial neural network (ANN) memberikan performa yang terbaik dibandingkan dengan menggunakan algoritma support vector machine (SVM) untuk memprediksi nilai kredit modal kerja yang disetujui bank.

\section{KESIMPULAN}

Dari hasil penelitian yang dilakukan dalam penelitian ini dari tahap awal hingga tahap pengujian model dengan menggunakan algoritma support vector machine (SVM) yang dikomparasi dengan algoritma artificial neural network (ANN) untuk memprediksi nilai kredit modal kerja yang disetujui oleh bank umum, telah didapatkan jawaban dari pertanyaanpertanyaan penelitian yang telah diidentifikasi sebelumnya, yaitu :

a. Dari eksperimen yang dilakukan pada algoritma support vector machine (SVM) dengan menggunakan kernel dot baik dilihat pada akurasi 
dan RMSE memberikan hasil evaluasi yang lebih baik dari pada kernel radial dan polynomial, yaitu akurasi yang didapat sebesar $=68,8 \%$ dan RMSE $=$ $11928,594$.

b. Sedangkan hasil dari pengujian dengan algoritma artificial neural network (ANN) dengan menentukan nilai parameter trining cycle yaitu 500, untuk nilai parameter learning-rate yaitu 0.3 dan nilai parameter momentum yaitu 0.2 dengan hidden layer adalah 1 dan hiddden layer size atau neuron 3, 5 dan 9, maka didapatkan hasil akurasi sebesar $=84,7 \%$ dan nilai RMSE sebesar = 5806,350 menggunakan hidden layer size/neuron 9.

c. Dari hasil komparasi menggunakan kedua algoritma diatas dapat disimpulkan bahwa algoritma artificial neural network (ANN) memiliki performa yang lebih baik dibandingkan dengan algoritma support vector machine (SVM).

\section{DAFTAR PUSTAKA}

Firdaus R, Ariyanti M. (2011). Manajemen Perkreditan Bank Umum. Bandung: Alfabeta,

Gupta M., Jin, and Homma. (2003). Static And Dynamic Neural Network From Fundamentals To Advanced Theory. Ed. John Wiley \& Sons, Inc., Hoboken, New Jersey. 8 Desember 2015 <http://homepage.usask.ca/ mmg864/>.

Sreelakshmi, Kumar. (2015)."Performance Evaluation of Short Term Wind Speed Prediction Techniques." IJCSNS International Journal of Computer Science and Network Security, Vol.8 No.8. 2008. 5 November 2015 <http://paper.ijcsns.org/07_book/200808/200808 24.pdf>.

Behzad M., Asghari K., and Coppola, (2015). Emery A. "Comparative Study of SVMs and ANNs in Aquifer Water Level Prediction." Journal of Computing in Civil Engineering, September 2010. Ebsco. 10 November 2015 <http://search.ebscohost.com>.

Alamili. (2011). Exchange Rate Prediction using Support Vector Machines A comparison with Artificial Neural Networks. Den Haag: Delft University Of Technology.

Fuqing Y., Kumar U., and Galar D. (2013). "A Comparative Study Of Artificial Neural Networks And Support Vector Machine For Fault Diagnosis." International Journal of Performability Engineering Vol. 9, No. 1, pp. 49-60, January Ebsco. 10 November 2015 <http://search.ebscohost.com>.
Wasito, Budi. .(2013). Kajian Penerapan Artificial Neural Network Untuk Memprediksi Harga Saham Mustika Ratu Dengan Metode Support Vector Machines Dan Multi Layer Perception. Jakarta: STMIK Nusa Mandiri.

Suryadi, Usep T. (2015). "Komparasi support vector machine dan neural network untuk prediksi kelulusan sertifikasi benih kentang. "Seminar Nasional Informatika, November 2015. Ebsco. 2 Desember 2015 <http:// search. ebscohost. com>.

Shukla, A., Tiwari, R., and Kala, R. (2010). Real Life Application of Soft Computing. CRC Press, 2010.

Bramer, M. (2007). Principles of Data Mining. London: Springer-Verlag

Santosa, Budi. , (2007). Data Mining: Teknik Pemanfaatan Dataa Untuk Keperluan Bisnis. Yogyakarta: Graha Ilmu.

Larose. .(2006). Data Mining Methods and Models. Hoboken, New Jersey, United States of America: John Wiley \& Sons, Inc. 